\title{
Faktor-Faktor Yang Berhubungan Dengan Pemeriksaan Antenatal Care (Anc) Pada Ibu Hamil Di Klinik Bersalin Titi Safitri Kota Jambi Tahun 2019
}

\author{
Rubiyati \\ Akademi Kebidanan Budi Mulia Jambi
}

Informasi Artikel :

Diterima : 16 Oktober 2019

Diperbaiki : 18 Oktober 2019

Disetujui : 02 November 2019

"Korespondensi Penulis :

Rubiyati814@gmail.com

\section{A B S T R A K}

Menurut data hasil riset kesehatan dasar (Ristekdas) tahun 2013, hamper seluruh ibu hamil di Indonesia $(95,4 \%)$ sudah melakukan pemeriksaan kehamilan (K1) dengan frekuensi minimal 4 kali selama masa kehamilan nya adalah $83.5 \%$. Adapun untuk cakupan pemeriksaan pertama pada pemeriksaan pertama adalah $81.6 \%$ dan frekuensi ANC 1-1-2 atau K4 (minimal 1 kali pada trimester pertama, minimal 1 kali pada trimester kedua dan minimal 2 kali pada trimester ketiga) sebesar $70.4 \%$. Penelitian ini merupakan penelitian analitik dengan pendekatan metode cross sectional yaitu suatu penelitian untuk mempelajari dinamika korelasi antara faktor-faktor resiko dengan efek, dengan cara pendekatan, observasi atau pengumpulan data sekaligus pada suatu saat / point time approach. Sampel pada penelitian ini berjumlah 30 Responden, variabel yang digunakan adalah pengetahuan, sikap, social ekonomi, dukungan suami, dan pengalaman. Hasil penelitian adalah terdapat hubungan yang signifikan antara pengetahuan, sikap, social ekonomi, dukungan suami, pengalaman dengan pemeriksaan ANC pada ibu hamil di Klinik Bersalin Titi Safitri Kota Jambi Tahun 2019. Diharapkan dengan adanya penelitian ini dapat menambah pengetahuan ibu hamil tentang pentingnya pemeriksaan kehamilan untuk mendeteksi secara dini kelainan dan masalah yang bisa terjadi pada masa kehamilan.

Kata Kunci : Pengetahuan, Sikap, Sosial Ekonomi, Dukungan Suami, Pengalaman, Pemeriksaan ANC

\section{ABSTRACT}

According to data from basic health research (Ristekdas) in 2013, almost all pregnant women in Indonesia (95.4\%) had already performed antenatal care (K1) with a frequency of at least 4 times during her pregnancy period of $83.5 \%$. As for the scope of the first examination at the first examination is $81.6 \%$ and the frequency of ANC 1-1-2 or K4 (at least 1 time in the first trimester, at least 1 time in the second trimester and at least 2 times in the third trimester) of 70.4\%. This research is an analytical research with cross sectional approach, which is a study to study the dynamics of the correlation between risk factors and effects, by way of approach, observation or data collection at the same time / point time approach. The sample in this study amounted to 30 respondents, the variables used were knowledge, attitudes, socioeconomic, husband support, and experience. The results of the study are that there is a significant relationship between knowledge, attitude, socioeconomic, husband's support, experience with ANC examination in pregnant women at the Titi Safitri Maternity Clinic in Jambi City in 2019. It is hoped that this research can add to the knowledge of pregnant women about the importance of antenatal care for early detection of abnormalities and problems that can occur during pregnancy

Keywords : Knowledge, Attitude, Socio-Economy, Husband Support, Experience, ANC Examination 


\section{PENDAHULUAN}

Pada umumnya kehamilan berkembang dengan normal dan menghasilkan kelahiran bayi sehat cukup bulan melalui jalan lahir, namun ini kadang tidak sesuai dengan yang diharapkan. Sulit sekali ingin mengetahui sebelumnya bahwa kehamilan akan menjadi masalah. Oleh karena itu pelayanan antenatal care (ANC) merupakan cara penting untuk memonitor dan mendukung ibu hamil normal dan mendeteksi ibu dengan kehamilan normal. ${ }^{1}$

Antenatal care sangatlah penting diketahui oleh ibu hamil karena dapat membantu mengurangi angka kematian ibu dan bayi. Keuntungan yang lain yaitu untuk menjaga agar selalu sehat selama masa hamil. Persalinan dan nifas serta mengusahakan bayi yang dilahirkan sehat, memantau kemungkinan adanya resikoresiko kehamilan, dan merencanakan penatalaksanaan yang optimal terhadap kehamilan resiko tinggi serta menurunkan morbiditas dan mortalitas ibu dan janin perinatal. $^{2}$

Kematian Ibu menurut World Health Organization (WHO) adalah kematian yang terjadi pada saat kehamilan, persalinan atau dalam 42 hari setelah persalinan dengan penyebab yang berhubungan langsung atau tidak langsung dari kehamilan atau persalinannya. Penyebab langsung kematian tersebut dikenal dengan Trias Klasik yaitu perdarahan (28\%), Eklamsia (24\%) dan infeksi (11\%). Sedangkan penyebab tidak langsung antara lain adalah ibu hamil menderita penyakit atau komplikasi lain yang sudah ada sebelum kehamilan, misalnya hipertensi, penyakit jantung, diabetes, hepatitis, anemia, malaria. Penyebab tersebut sebenarnya dapat dicegah dengan pemeriksaan kehamilan yang memadai. ${ }^{3}$

Faktor-faktor yang mempengaruhi pemeriksaan ANC pada ibu hamil antara lain: umur, pengetahuan, sikap, ekonomi/penghasilan, minat, pekerjaan, faktor fisik, dukungan suami dan keluarga, pengalaman. ${ }^{4}$

Minimnya pengetahuan tentang resikoresiko kehamilan yang diakibatkan karena rendah tingkat pendidikan, pemeliharaan kehamilan, pengetahuan tentang gizi dalam kehamilan, keadaan ekonomi dan sebagainya. Pada umumnya keterbatasan ekonomi keluarga menjadi faktor yang dominan dalam mempengaruhi kematian maternal selain pengetahuan atau pendidikan.

\section{METODE PENELITIAN}

Penelitian ini merupakan penelitian analitik dengan pendekatan metode cross sectional yaitu suatu penelitian untuk mempelajari dinamika korelasi antara faktorfaktor resiko dengan efek, dengan cara pendekatan, observasi atau pengumpulan data sekaligus pada suatu saat / point time approach (Notoatmodjo, 2011). Tujuan penelitian ini adalah untuk mengetahui Faktor-Faktor yang berhubungan dengan Pemeriksaan Antenatal Care (ANC) pada ibu Hamil di Klinik Bersalin Titi Safitri Kota Jambi Tahun 2019.

Metode pengumpulan data dalam penelitian inni meliputi data primer dan data sekunder. Adapun metode analisa data yang digunakan adalah analisa univariat dan bivariat yang bertujuan untuk mengetahui distribusi frekuensi dari variabel independen dan dependen.

\section{HASIL PENELITIAN}

Tabel 1 Hubungan antara Pengetahuan Ibu Hamil dengan Pemeriksaan ANC

\begin{tabular}{|c|c|c|c|c|c|c|c|c|}
\hline \multirow{3}{*}{$\begin{array}{l}\mathbf{N} \\
\mathbf{0}\end{array}$} & \multirow{3}{*}{ Pengetahuan } & \multicolumn{4}{|c|}{ Pemeriksaan ANC } & \multirow{2}{*}{\multicolumn{2}{|c|}{ Total }} & \multirow{3}{*}{$\begin{array}{c}\text { P- } \\
\text { value }\end{array}$} \\
\hline & & \multicolumn{2}{|c|}{$\begin{array}{c}\text { Kurang } \\
\text { Baik }\end{array}$} & \multicolumn{2}{|c|}{ Baik } & & & \\
\hline & & $\mathbf{f}$ & $\%$ & $\mathbf{f}$ & $\%$ & $\mathbf{F}$ & $\%$ & \\
\hline 1 & Kurang Baik & 4 & 11,8 & 0 & 0 & 4 & 11,8 & 0,005 \\
\hline 2 & Baik & 6 & 17,6 & 24 & 70,6 & 30 & 88,2 & \\
\hline & Total & 10 & 29,4 & 24 & 70 & 34 & 100 & \\
\hline
\end{tabular}

Berdasarkan tabel 1 diatas tentang

Hubungan antara pengetahuan ibu hamil dengan pemeriksaan ANC, diketahui dari 4 responden dengan pengetahuan kurang baik melakukan pemeriksaan ANC dengan kurang baik sebanyak $11,8 \%$ dan sebanyak 6 responden yang memiliki pengetahuan baik melakukan pemeriksaan ANC dengan baik sebanyak 70,6\%.

Tabel 2 Hubungan Antara Sikap Ibu Hamil Dengan Pemeriksaan

\begin{tabular}{|c|c|c|c|c|c|c|c|c|}
\hline \multirow{3}{*}{$\begin{array}{l}\mathbf{N} \\
\mathbf{0}\end{array}$} & \multirow{3}{*}{ Sikap } & \multicolumn{4}{|c|}{ Pemeriksaan ANC } & \multirow{2}{*}{\multicolumn{2}{|c|}{ Total }} & \multirow{3}{*}{$\begin{array}{c}\text { P- } \\
\text { value }\end{array}$} \\
\hline & & \multicolumn{2}{|c|}{$\begin{array}{c}\text { Kurang } \\
\text { Baik }\end{array}$} & \multicolumn{2}{|c|}{ Baik } & & & \\
\hline & & $\mathbf{f}$ & $\%$ & $\mathbf{f}$ & $\%$ & $\mathbf{F}$ & $\%$ & \\
\hline 1 & Negatif & 8 & 23,5 & 8 & 23,5 & 16 & 47 & \multirow{3}{*}{0,023} \\
\hline 2 & Positif & 2 & 5,9 & 16 & 47,1 & 18 & 53 & \\
\hline & Total & 10 & 29,4 & 24 & 70,6 & 34 & 100 & \\
\hline
\end{tabular}


Jurnal Kebidanan :Jurnal Medical Science Ilmu Kesehatan Akademi Kebidanan Budi Mulia Palembang Volume.9 No.2, Desember 2019

Berdasarkan tabel diatas diketahui bahwa dari 8 responden yang memiliki sikap negatif sebnayak 23,5 \% responden melakukan pemeriksaan ANC dengan kurang baik dan sebanyak 16 responden dengan sikap positif sebanyak 47,1\% melakukan pemeriksaan ANC dengan baik

\section{Hubungan antara Penghasilan Keluarga dengan Pemeriksaan ANC}

\begin{tabular}{|c|c|c|c|c|c|c|c|c|}
\hline \multirow{3}{*}{$\begin{array}{l}\mathbf{N} \\
\mathbf{o}\end{array}$} & \multirow{3}{*}{$\begin{array}{c}\text { Penghasilan } \\
\text { keluarga }\end{array}$} & \multicolumn{4}{|c|}{ Pemeriksaan ANC } & \multirow{2}{*}{\multicolumn{2}{|c|}{ Total }} & \multirow{3}{*}{$\begin{array}{c}P \text { - } \\
\text { value }\end{array}$} \\
\hline & & \multicolumn{2}{|c|}{$\begin{array}{c}\text { Kurang } \\
\text { Baik }\end{array}$} & \multicolumn{2}{|c|}{ Baik } & & & \\
\hline & & f & $\%$ & f & $\%$ & $\mathbf{F}$ & $\%$ & \\
\hline 1 & $\begin{array}{l}\text { Menengah } \\
\text { ke bawah }\end{array}$ & 6 & 17,6 & 3 & 8,8 & 9 & 26,4 & \\
\hline 2 & $\begin{array}{l}\text { Menengah } \\
\text { ke atas }\end{array}$ & 4 & 11,8 & 21 & 61,8 & 25 & 73,6 & 0,009 \\
\hline & Total & 10 & 29,4 & 24 & 70,9 & 34 & 100 & \\
\hline
\end{tabular}

Berdasarkan tabel diatas diketahui bahwa dari 6 responden yang penghasilan keluarga menengah kebawah sebanyak $17,6 \%$ responden melakukan pemeriksaan ANC dengan kurang baik dan sebanyak 21 responden dengan penghasilan keluarga menengah keatas sebanyak $61,8 \%$ melakukan pemeriksaan ANC dengan baik.

\section{Hubungan antara Dukungan Suami Keluarga dengan Pemeriksaan ANC}

\begin{tabular}{|c|c|c|c|c|c|c|c|c|}
\hline \multirow{3}{*}{$\begin{array}{l}\mathbf{N} \\
\mathbf{o}\end{array}$} & \multirow{3}{*}{$\begin{array}{c}\text { Dukungan } \\
\text { suami }\end{array}$} & \multicolumn{4}{|c|}{ Pemeriksaan ANC } & \multirow{2}{*}{\multicolumn{2}{|c|}{ Total }} & \multirow{3}{*}{$\begin{array}{c}\text { P- } \\
\text { value }\end{array}$} \\
\hline & & \multicolumn{2}{|c|}{$\begin{array}{c}\text { Kurang } \\
\text { Baik }\end{array}$} & \multicolumn{2}{|c|}{ Baik } & & & \\
\hline & & $\mathbf{f}$ & $\%$ & $\mathbf{f}$ & $\%$ & $\mathbf{F}$ & $\%$ & \\
\hline 1 & Kurang baik & 8 & 23,5 & 6 & 17,6 & 14 & 41,2 & \multirow{3}{*}{0,006} \\
\hline 2 & Baik & 2 & 5,9 & 18 & 52,9 & 20 & 58,8 & \\
\hline & Total & 10 & 29,4 & 24 & 70,6 & 34 & 100 & \\
\hline
\end{tabular}

Berdasarkan tabel diatas diketahui bahwa dari 8 responden dengan dukungan suami kurang baik sebanyak 23,5\% melakukan pemeriksaan ANC dengan kurang baik dan sebanyak 18 responden dengan dukungan suami baik sebanyak 52,9 \% melakukan pemeriksaan ANC dengan baik.

\section{Hubungan antara Pengalaman Ibu dengan Pemeriksaan ANC}

\begin{tabular}{|c|c|c|c|c|c|c|c|c|}
\hline \multirow{3}{*}{$\begin{array}{l}\mathbf{N} \\
\mathbf{o}\end{array}$} & \multirow{3}{*}{$\begin{array}{c}\text { Pengalaman } \\
\text { Ibu }\end{array}$} & \multicolumn{4}{|c|}{ Pemeriksaan ANC } & \multirow{2}{*}{\multicolumn{2}{|c|}{ Total }} & \multirow{3}{*}{$\begin{array}{c}\text { P- } \\
\text { value }\end{array}$} \\
\hline & & \multicolumn{2}{|c|}{$\begin{array}{c}\text { Kurang } \\
\text { Baik }\end{array}$} & \multicolumn{2}{|c|}{ Baik } & & & \\
\hline & & $\mathbf{f}$ & $\%$ & $\mathbf{f}$ & $\%$ & $\mathbf{F}$ & $\%$ & \\
\hline 1 & $\begin{array}{l}\text { Belum } \\
\text { Berpengalaman }\end{array}$ & 9 & 26,5 & 9 & 26,5 & 18 & 53 & \\
\hline 2 & Berpengalaman & 1 & 2,9 & 15 & 44,1 & 16 & 47 & 08 \\
\hline & Total & 10 & 29,4 & 24 & 70,6 & 34 & 100 & \\
\hline
\end{tabular}

Berdasarkan tabel diatas diketahui bahwa dari 9 responden yang belum memiliki pengalaman hamil sebanyak 26,5\% melakukan pemeriksaan ANC dengan kurang baik dan sebanyak 15 responden yang berpengalaman sebanyak $44,1 \%$ responden melakukan pemeriksaan ANC dengan baik.

\section{PEMBAHASAN}

\section{Hubungan Antara Pengetahuan Ibu} Hamil Dengan Pemeriksaan ANC

Hasil analisis dari 34 resonden tentang Hubungan antara pengetahuan ibu hamil dengan pemeriksaan ANC, diketahui dari 4 responden dengan pengetahuan kurang baik melakukan pemeriksaan ANC dengan kurang baik sebanyak 11,8 \% dan sebanyak 6 responden yang memiliki pengetahuan baik melakukan pemeriksaan ANC dengan baik sebanyak 70,6 \%.

Faktor yang mempengaruhi pengetahuan mengenai pemeriksaan ANC yaitu pengalaman, informasi dan sosial budaya responden. Dengan memberikan informasi tentang manfaat pemeriksaan ANC diharapkan akan terjadi peningkatan pengetahuan, sikap dan perilaku kesehatan dalam diri individu / kelompok sasaran yang berdasarkan kesadaran dan kemauan individu yang bersangkutan.

Hasil penelitian di atas menunjukan bahwa semakin baik pengetahuan yang dimiliki tentang pemeriksaan ANC maka akan semakin baik pula kepatuhan ibu dalam melakukan pemeriksaan ANC. Sebaliknya semakin kurang baik pengetahuan yang 
Jurnal Kebidanan :Jurnal Medical Science Ilmu Kesehatan Akademi Kebidanan Budi Mulia Palembang Volume.9 No.2, Desember 2019

dimiliki tentang pemeriksaan ANC maka akan semakin kurang baik pula kepatuhan ibu dalam melakukan pemeriksaan ANC. Dapat disimpulkan bahwa pengetahuan yang dimiliki ibu akan berpengaruh pada perilaku yang dilakukannya dalam melakukan pemeriksaan ANC.

Hal ini sesuai dengan teori menurut Notoatmodjo (2012) bahwa pengetahuan kesehatan akan berpengaruh kepada perilaku sebagai jangka menengah (intermediat impact) dari pendidikan kesehatan. Selanjutnya perilaku kesehatan akan berpengaruh pada meningkatnya indikator kesehatanmasyarakat sebagai keluaran (out come) pendidikan kesehatan. ${ }^{5}$

Upaya-upaya yang perlu dilakukan untuk meningkatkan pengetahuan responden tentang pemeriksaan ANC adalah dilakukannya pendidikan kesehatan mengenai pemeriksaan ANC, menjelaskan dengan menggunakna bahasa yang mudah dimengerti agar responden dapat memahami dengan baik dan juga dengan cara leaflet, brosur, dan kegiatan promotif lainnya seperti melakukan diskusi bersama responden.

\section{Hubungan Antara Sikap Ibu Hamil Dengan Pemeriksaan ANC}

Berdasarkan hasil analisis terhadap 34 responden diketahui bahwa dari 8 responden yang memiliki sikap negatif sebanyak 23,5 $\%$ responden melakukan pemeriksaan ANC dengan kurang baik dan sebanyak 16 responden dengan sikap positif sebnayak $47,1 \%$ melakukan pemeriksaan ANC dengan baik.

Adapun sikap yang positif terhadap pemeriksaan ANC adalah dengan memberikan respon atau tanggapan yang baik dalam merespon bermacam masalah pemeriksaan ANC. Sedangkan sikap negatif adalah tidak merespon atau menanggapi dengan baik dalam hal merespon bermacam masalah dalam ketekunan dalam melakukan pemeriksaan ANC. ${ }^{6}$

Sikap terhadap nilai-nilai kesehatan tidak selalu terwujud didalam suatu tindakan nyata, terkadang sikap terbentuk karena situasi yang dialami responden tersebut.
Dalam hal ini sikap responden negatif kemungkinan karena kurangnya informasi yang didapat. Sebagian menganggap remeh, tidak peduli atau kurang kesadaran terhadap pengetahuan yang didapat tentang pemeriksaan ANC. Hal ini tentu dapat membuat persepsi yang menyimpang terhadap ketekunan dalam melakukan pemeriksaan ANC. Pengetahuan responden tentang pemeriksaan ANC yang masih kurang dapat menyebabkan sikap responden tersebut masih belum kearah yang positif.

Upaya-upaya yang perlu dilakukan untuk membentuk sikap positif responden tentang upaya menurunkan intensitas dismenore primer yaitu dengan diberikan pendidikan kesehatan berkaitan dengan sikap yang baik dan tidak baik tentang pemeriksaan ANC dengan cara memberikan pengetahuan dan menanamkan nilai-nilai serta persepsi positif. Hal ini dapat dilakukan dengan memberikan leaflet dan informasi seperti spanduk dalam upaya memberikan pengetahuan secara luas agar terbentuk sikap yang positif. Selain itu diharapkan petugas kesehatan juga ikut berperan aktif dalam penanganan sikap responden terhadap upaya menurunkan intensitas dismenore primer agar tidak membuat perilaku responden menjadi kurang baik.

\section{Hubungan Antara Penghasilan Kelurga Dengan Pemeriksaan ANC}

Berdasarkan hasil analsis terhadap 34 responden diketahui bahwa dari 6 responden yang penghasilan keluarga menengah kebawah sebanyak $17,6 \%$ responden melakukan pemeriksaan ANC dengan kurang baik dan sebanyak 21 responden dengan penghasilan keluarga menengah keatas sebanyak $61,8 \%$ melakukan pemeriksaan ANC dengan baik.

Dari hasil penelitian yang dilakukan di Klinik Bersalin Titi Safitri diketahui bahwa sebagian besar status ekonomi keluarga ibu hamil berada pada status menengah keatas hal ini didukung dengan masyarakat yang tinggal diperkotaan dan pekerjaan dari keluaraga yang memadai 
Jurnal Kebidanan :Jurnal Medical Science Ilmu Kesehatan Akademi Kebidanan Budi Mulia Palembang Volume.9 No.2,

Desember 2019

yang ditunjang dengan pendidikan yang dimiliki keluarga cukup tinggi.

Status ekonomi memiliki hubungan dengan kepatuhan ibu dalam melakukan pemeriksaan ANC karena persepsi dari masyarakat yaitu untuk melakukan pemeriksaan pada ibu hamil, keluarga harus memiliki cukup uang. Sehingga untuk keluarga yang memiliki status ekonomi menengah kebawah jarang melakukan pemeriksaan dikarnakan biaya yang harus dikeluarkan saat melakukan pemeriksaan. Dalam hal ini sebenarnya pemerintah telah berupaya untuk mengatasinya yaitu dengan adanya layanan pemeriksaan dan pemberian vitamin pada ibu hamil secara gratis di Puskesmas, namun masih banyak masyarkat yang belum mengetahui hal tersebut. Upaya yang dilakukan yaitu dengan melakukan sosialisasi kepada masyarakat untuk dapat melakukan pemeriksaan ANC secara rutin sesuai dengan usia kehamilan di Puseksmas secara gratis sehingga ibu hamil dapat mencegah/ mendeteksi secara dini terjadinya komplikasi pada masa kehamilan dan persalinan.

\section{Hubungan Antara Dukungan Suami Dengan Pemeriksaan ANC}

Berdasarkan hasil analisis terhadap 34 responden diketahui bahwa dari 8 responden dengan dukungan suami kurang baik sebanyak 23,5\% melakukan pemeriksaan ANC dengan kurang baik dan sebanyak 18 responden dengan dukungan suami baik sebanyak 52,9 \% melakukan pemeriksaan ANC dengan baik.

Hasil penelitian tersebut menunjukan bahwa semakin tinggi dukungan yang diberikan oleh suami/ keluarga maka semakin baik tingkat kepatuhan ibu dalam melakukan pemeriksaan ANC. Namun ada beberapa responden yang memiliki dukungan yang baik dari suami/ keluarga namun memiliki kepatuhan yang kurang baik dalam melakukan pemeriksaan ANC hal ini disebabkan karena masih kurangnya kesadaran ibu dalam melakukan pemeriksaan ANC.

Untuk meningkatkan dukungan suami/ keluarga kepada ibu hamil beberapa upaya yang harus dilakukan yaitu dengan memberikan informasi atau mendidik keluarga ibu hamil tentang tugas keluarga dalam memberikan dukungan kepada ibu hamil untuk melakukan kunjungan ANCdan keluarga harus menciptakan suasana yang menguntungkan bagi kesehatan ibu hamil, serta hubungan timbal balik antar anggota keluarga dengan lembaga kesehatan yang menunjukkan pemanfaatan dengan fasilitasfasilitas kesehatan yang ada.

\section{Hubungan Antara Pengalaman Ibu Dengan Pemeriksaan ANC}

Berdasarkan hasil analisi diketahui bahwa dari 9 responden yang belum memiliki pengalaman hamil sebanyak $26,5 \%$ melakukan pemeriksaan ANC dengan kurang baik dan sebanyak 15 responden yang berpengalaman sebanyak $44,1 \%$ responden melakukan pemeriksaan ANC dengan baik.

Semakin berpengalaman seorang ibu dalam masa kehamilanmaka kesdaran untuk melakukan pemeriksaan ANC semakin tinggi hal ini ditunjukan dengan hasil analisis dimana sebanyak $15 \quad(44,1 \%)$ responden yang berpengalaman telah melakukan pemeriksaan ANC dengan teratur sesuai denga usia kehamilan, hanya $1(2,9 \%)$ responden yang memiliki pengalaman namun tidak melakukan pemeriksaan ANC dengan baik atau sesuai dengan usia kehamilan.

\section{KESIMPULAN}

Berdasarkan hasil penelitian ini dapat disimpulkan terdapat hubungan yang signifikan antara pengetahuan, sikap, social ekonomi, dukungan suami, pengalaman dengan pemeriksaan ANC pada ibu hamil di Klinik Bersalin Titi Safitri Kota Jambi Tahun 2019

\section{DAFTAR PUSTAKA}

1. Kusmiyati, Dkk. 2009. Perawatan Ibu hamil.Penerbit: Fitramaya. Yogyakarta.

2. Fatimah Jahra Ritonga, Nur Asiah.Faktorfaktor yang Mempengaruhi Ibu Hamil 
Jurnal Kebidanan :Jurnal Medical Science Ilmu Kesehatan Akademi Kebidanan Budi Mulia Palembang Volume.9 No.2, Desember 2019

dalam Melakukan Pemeriksaan Antenatal

Care. https://jurnal.usu.ac.id > index.php >

jkk> article > download.

3. Depkes RI. 2010 Rencana Pengembangan Jangka Panjang Kesehatan Indonesia Tahun 2005-2025. Jakarta.

4. Sulistyawati, Ary.2009. Asuhan Kebidanan Pada Masa Kehamilan, Yogyakarta.Penerbit: Salemba Medika

5. Notoatmodjo, Soekijdo. 2010. Metodologi PenelitianKesehatan. Jakarta: PT RinekaCipta.

6. Dewi, dkk.2011. Asuhan Kehamilan Untuk Kebidanan.Salemba. Yogyakarta: Salemba Medika

7. Rahmawati, I. N ,Budiati, T \& Rahmawati, C.2008. Panduan Praktikum Prosedur Pemeriksaan Fisik Antenatal. Depok: UI 